\title{
Structural characterization of lead sulfide thin films by means of X-ray line profile analysis
}

\author{
N CHOUDHURY* and B K SARMA \\ Department of Physics, Gauhati University, Guwahati 781 014, India
}

MS received 25 May 2008; revised 25 January 2009

\begin{abstract}
X-ray diffraction patterns of chemically deposited lead sulphide thin films have been recorded and $X$-ray line profile analysis studies have been carried out. The lattice parameter, crystallite size, average internal stress and microstrain in the film are calculated and correlated with molarities of the solutions. Both size and strain are found to contribute towards the broadening of $\mathrm{X}$-ray diffraction line. The values of the crystallite size are found to be within the range from $22-33 \mathrm{~nm}$ and the values of strain to be within the range from $1.0 \times 10^{-3}-2.5 \times 10^{-3}$.
\end{abstract}

Keywords. PbS thin films; X-ray diffraction; average internal stress; microstrain.

\section{Introduction}

Lead sulfide $(\mathrm{PbS})$ is a semiconducting chalcogenide with a direct bandgap of $0.41 \mathrm{eV}$ and has a cubic structure. Owing to their suitable bandgaps, $\mathrm{PbS}$ thin films are widely used in IR detectors. PbS is suitable for the detection of the radiation between wavelengths 1 and $3 \mu \mathrm{m}$. This detector can operate at any temperature between 77 and $300 \mathrm{~K}$ (Johnson 1984). The possibility of using very thin $(20-60 \mathrm{~nm})$ chemically deposited $\mathrm{PbS}$ films as solar control coatings have been discussed by many workers (Nair et al 1989). Analyses of the mechanism of photoconductivity in $\mathrm{PbS}$ thin films are also widely reported (Espevik et al 1971). Chemical bath deposition (CBD) is one of the standard methods used for preparing $\mathrm{PbS}$ films (Choudhuri et al 1981; Gadave et al 1994; Popa et al 2006; Ubale et al 2007). This method is less expensive, easy to handle, allowing deposition of films on a large area and on various substrates (Dhumure and Lokhande 1993; Devi et al 2007). Although many investigations on $\mathrm{PbS}$ thin films deposited by CBD method have been done so far it is found that not much results are reported on structural attributes of the films and their correlation to other deposition properties. Keeping in view all these aspects, an experimental study on the structural characterization of chemically deposited $\mathrm{PbS}$ films has been undertaken. A correlation between molarity and different structural parameters has been highlighted in the present work.

\footnotetext{
*Author for correspondence (navapkc@yahoo.co.in)
}

\section{Experimental}

In the present work, glass slides of dimension, $35 \times 20 \times$ $1.35 \mathrm{~mm}$, were used as substrates. They were suitably cleaned in detergent, chromic acid and distilled water. Solutions of lead acetate of four different concentrations $(0.25 \mathrm{M}, 0.50 \mathrm{M}, 0.75 \mathrm{M}$ and $1.00 \mathrm{M})$ were prepared and $\mathrm{NH}_{4} \mathrm{OH}$ solution was then added slowly to maintain $\mathrm{pH}$ of the solution at around 11. Then the equimolar solution of thiourea was added to the solution. The substrates were introduced vertically into the solution with the help of a suitably designed substrate holder. The glass substrates were kept in the solution for $24 \mathrm{~h}$ at room temperature for deposition of films. After deposition, the substrates were taken out and thoroughly washed and rinsed with doubly distilled water and dried in air. Structural characterizations of the films were determined by X-ray diffraction method using Philips X-pert Pro diffractometer (PW 1830) at room temperature with $\mathrm{CuK} \alpha$ radiation.

\section{Determination of structural parameters}

\subsection{Lattice constant}

The chemical bath deposited $\mathrm{PbS}$ thin films possess facecentred cubic structure. It is confirmed by comparing the peak positions $(2 \theta)$ of the XRD patterns of the films with the standard X-ray powder diffraction data file (card no. 5-0592). The lattice constant ' $a$ ' for the cubic phase structure is determined by the relation

$$
a=d\left(h^{2}+k^{2}+l^{2}\right)^{1 / 2} .
$$

The corrected values of lattice constants are estimated from the Nelson-Riley plots. The Nelson-Riley curve is 
plotted between the calculated ' $a$ ' for different planes and the error function (Nelson and Riley 1945)

$$
f(\theta)=1 / 2\left(\cos ^{2} \theta / \sin \theta+\cos ^{2} \theta / \theta\right),
$$

and extrapolating the plot to $\theta=90^{\circ}$.

A typical Nelson-Riley plot for a $\mathrm{PbS}$ thin film is shown in figure 2 .

\subsection{Crystallite size}

The crystallite sizes of the nanocrystalline $\mathrm{PbS}$ film is estimated using Scherrer's formula

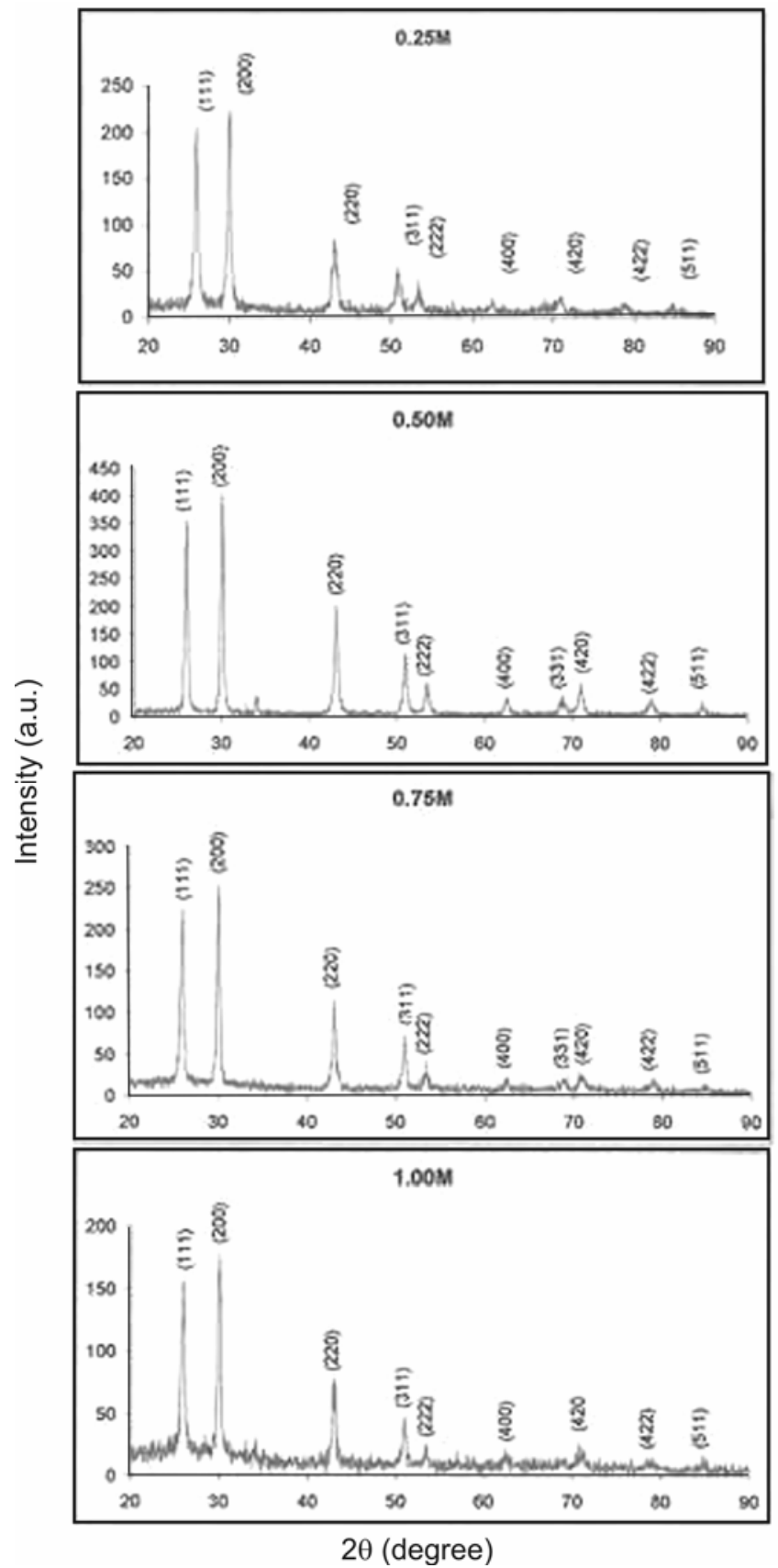

Figure 1. X-ray diffraction patterns of $\mathrm{PbS}$ films for different molarities.

$$
D=K \lambda / \beta_{2 \theta} \cos \theta,
$$

where the constant $K$ is taken to be $0.94, \lambda$ the wavelength of X-ray used which is $\mathrm{CuK} \alpha$ radiation $(\lambda=1.54 \AA)$, and $\beta_{2 \theta}$ the full width at half maximum of the diffraction peak corresponding to [111] plane.

\subsection{Average internal stress and microstrain}

It is found that lattice constant ' $a$ ' of the film deviates from its bulk value ' $a_{0}$ ' which is $5.936 \AA$. This shows that films are under strain. Apart from smallness of the crystallite size, presence of strains also contributes towards broadening of the diffraction line. The built-in average stresses developed in the film is determined by the relation (De and Misra 1997)

$$
S=\left\{\left(a_{0}-a\right) / a_{0}\right\} Y / 2 \sigma,
$$

where $a$ and $a_{0}$ are the lattice parameters of the thin film samples and bulk samples, respectively and the value $\varepsilon\left[=\left(a_{0}-a\right) / a_{0}\right]$ is obtained from W-H plot, $Y$ and $\sigma$ are the Young's modulus and Poisson's ratio of the bulk sample, respectively. For $\mathrm{PbS}$, the value of $\mathrm{Y}$ is $70 \cdot 2 \mathrm{GPa}$ and $\sigma$ is 0.28 (Weber 2003).

The total stress in the films is due to (i) differences in the thermal expansion coefficient of the films and substrate material and (ii) lattice mismatch between the material and the substrate and other crystallographic defects that may be present in the film. If the size and strain broadening is present simultaneously then the crystallite size and strain may be obtained from Williamson-Hall plot (Sengupta and Chatterjee 2002). In figure 4, W-H plot for the films are shown.

The slope of the plot represents average strain in the film whereas the intercept on $\beta^{*}$ axis gives the crystallite size according to the relation (Ungar and Borbely 1996)

$$
\beta \cos \theta / \lambda=1 / D+4 \varepsilon \sin \theta / \lambda,
$$

where $\beta$ is the full width at half maximum (FWHM), $D$ the average crystallite size and $\varepsilon$ the average strain.

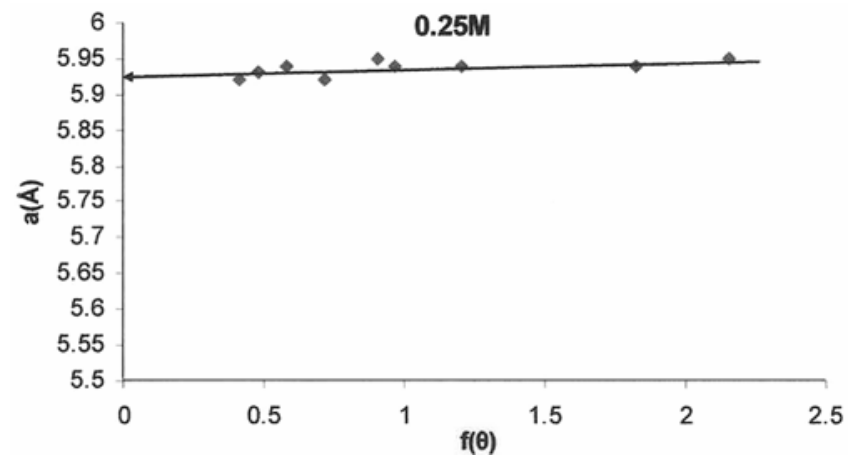

Figure 2. Nelson-Riley plot for a PbS thin film. 
Table 1. Structural parameters of $\mathrm{PbS}$ thin films deposited at room temperature (time of deposition, $24 \mathrm{~h}$ ).

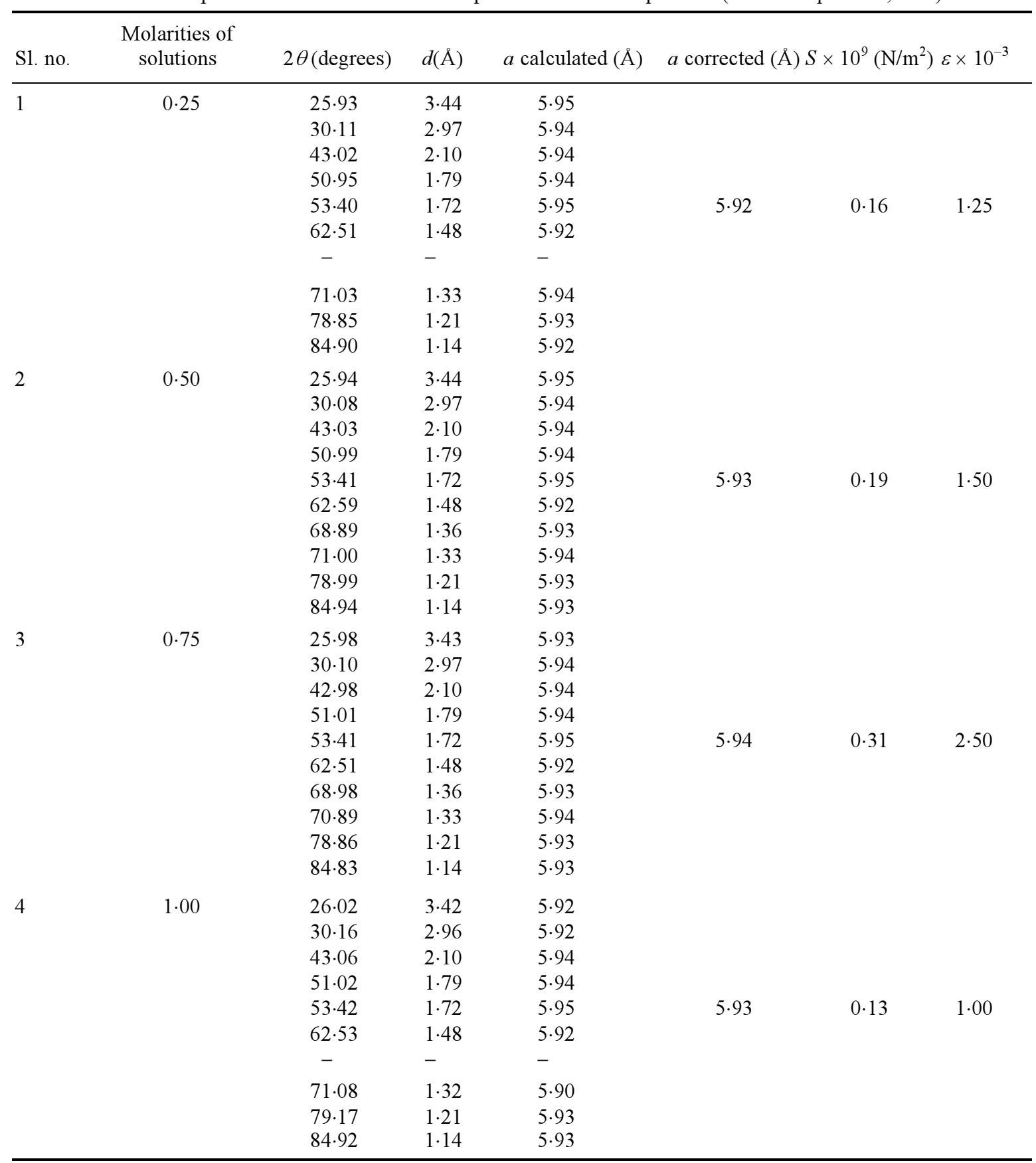

\section{Results and discussion}

$\mathrm{X}$-ray diffraction pattern of the $\mathrm{PbS}$ film for four different molarities of the solutions are shown in figure 1 . The $\mathrm{PbS}$ films are found to be polycrystalline in nature having $f c c$ structure. Well defined peaks of (111), (200), (220), (311), (222), (400), (331), (420), (422) and (511) reflections are observed in XRD pattern. The strong and sharp peaks suggest that the films deposited on glass substrates with different molarities are well crystallized (Cheng et al 2006).
The various structural parameters, e.g. corrected values of lattice constant $(a)$, average internal stress $(S)$ and microstrain $(\varepsilon)$ for $\mathrm{PbS}$ thin films deposited with different molarities are calculated and systematically represented in table 1. The values of lattice constant, crystallite size, average internal stress and microstrain are correlated with molarities of the solutions and are shown in figure 3 . The lattice constant ' $a$ ' is found to increase gradually with the solutions up to a molarity of 0.75 . Beyond $0.75 \mathrm{M}$ (molarity), there is a slight fall in the lattice constant (figure $3 i)$. The change in lattice constant for the deposited thin 
Table 2. Comparison of ' $D$ ' values for $\mathrm{PbS}$ thin films deposited at room temperature.

\begin{tabular}{lccc}
\hline & & \multicolumn{2}{c}{ Crystallite size $[D(\mathrm{~nm})]$} \\
\cline { 3 - 4 } S1. no. & Molarities of solutions & From Scherrer's formula & From W-H plot \\
\hline 1 & $0.25 \mathrm{M}$ & 22 & 22 \\
2 & $0.50 \mathrm{M}$ & 25 & 25 \\
3 & $0.75 \mathrm{M}$ & 29 & 33 \\
4 & $1.00 \mathrm{M}$ & 19 & 23 \\
\hline
\end{tabular}
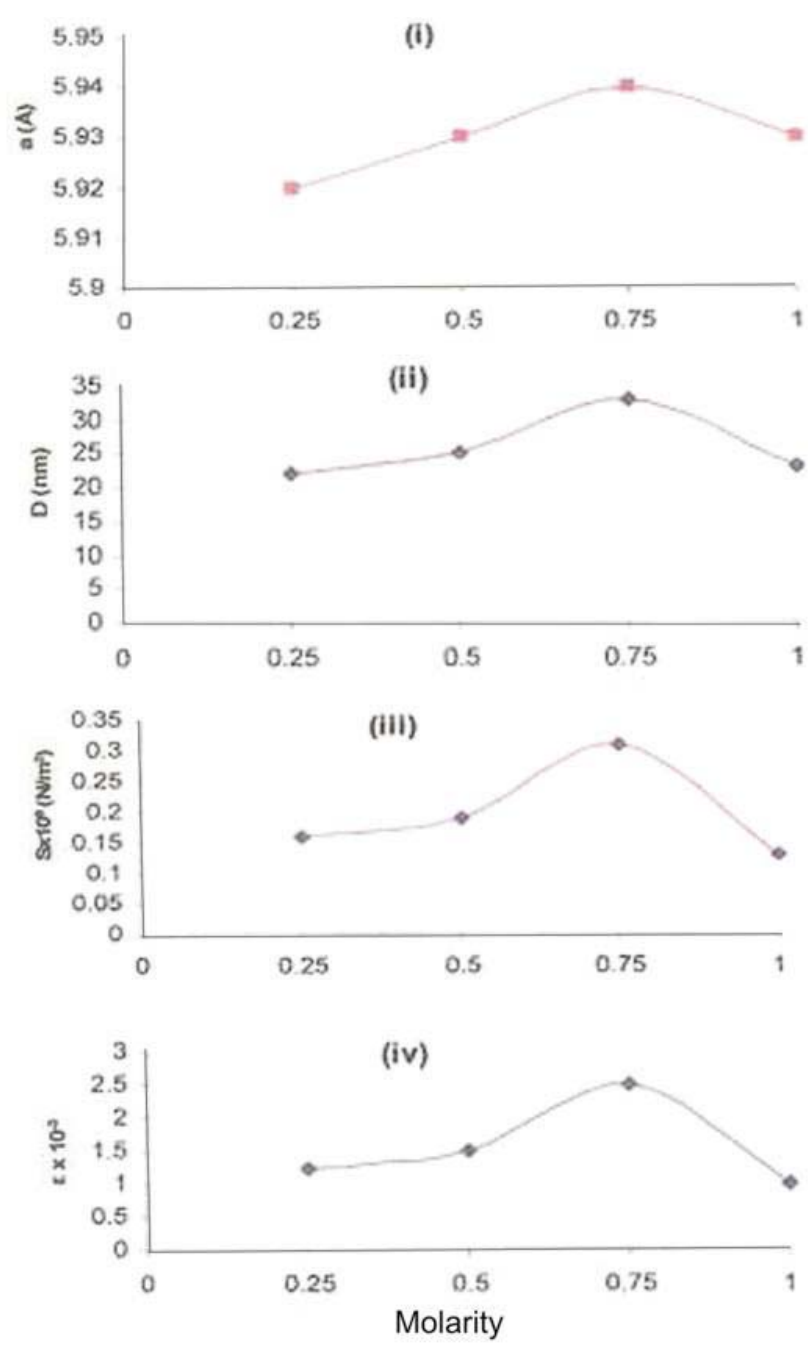

Figure 3. Variation of (i) lattice constant, (ii) crystallite size, (iii) average internal stress and (iv) microstrain with molarities in $\mathrm{PbS}$ films.

film over the bulk clearly suggests that the film grains are strained (Reichelt and Jiang 1990).

It is observed that with the increase in the molarities of the solutions there is a gradual increase in the crystallite size up to a molarity of $0 \cdot 75$. Beyond $0.75 \mathrm{M}$ (molarity) there is a slight fall in the crystallite size. Similar results are also reported earlier by us (Choudhury and Sarma 2008). The values of the average internal stress in the $\mathrm{PbS}$ films are determined by using relation (4). In figure 3 (iii), it is observed that at $0.75 \mathrm{M}$, the stress is maximum.
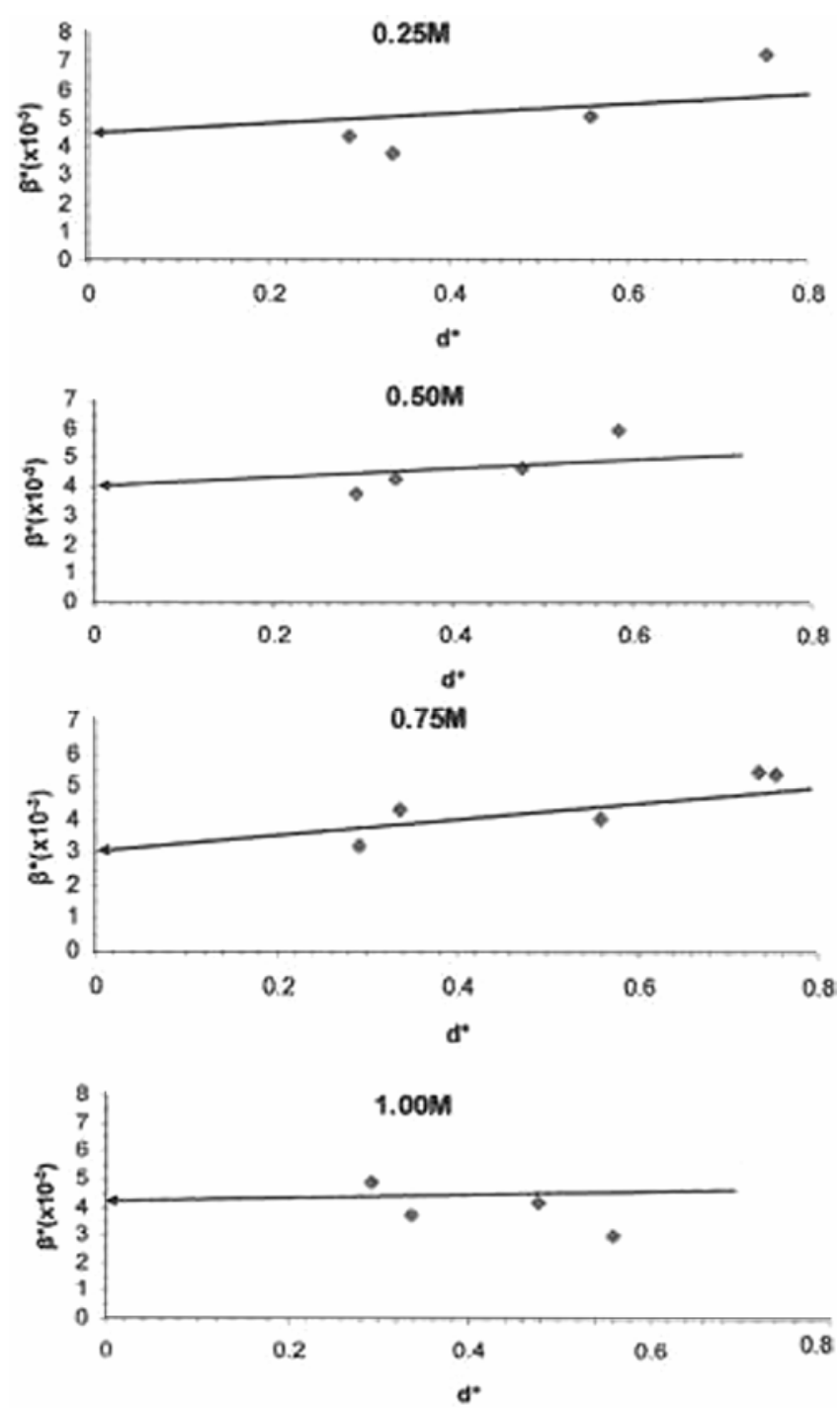

Figure 4. Williamson-Hall plots of $\mathrm{PbS}$ films for different molarities where $\beta^{*}=(\beta \cos \theta) / \lambda$ and $d^{*}=(2 \sin \theta) / \lambda$.

From the W-H plots of the films (figure 4), it has been confirmed that the X-ray line broadening in polycrystalline thin films of $\mathrm{PbS}$ is due to the presence of size effect as well as strain effect. The slopes of the $\mathrm{W}-\mathrm{H}$ plot represent average internal strain in the film while the inverse of the intercept at $\beta^{*}$ axis gives the crystallite size according to the relation (5). The values of the average crystallite size as determined from $\mathrm{W}-\mathrm{H}$ plot are shown in table 2 . 
The values of the microstrain in the $\mathrm{PbS}$ films determined from slope of the $\mathrm{W}-\mathrm{H}$ plot are shown in table 1 . In figure 3 (iv), it is observed that at $0.75 \mathrm{M}$, the microstrain is maximum.

\section{Conclusions}

The structural parameters like lattice constant, crystallite size, internal stress and strain of $\mathrm{PbS}$ thin films deposited by CBD technique using equimolar but with different individual molarities of the solutions are determined and are found to be affected by the molarities of the solutions. The lattice constant, crystallite size, internal stress and strain in the films are found to be maximum for solution with molarity $0 \cdot 75$. Both size and strain effects on broadening of X-ray diffraction line are found to be present in the films.

\section{Acknowledgements}

The authors are thankful to USIC, Gauhati University, Guwahati, for providing XRD facility.

\section{References}

Cheng T et al 2006 Bull. Mater. Sci. 29701
Choudhury N and Sarma B K 2008 Indian J. Pure \& Appl. Phys. 46261

Choudhuri T K, Acharya H N and Nayak B B 1981 Thin Solid Films 83 L169

De C K and Misra N K 1997 Indian J. Phys. A71 535

Devi R, Purkayastha P, Kalita P K and Sarma B K 2007 Bull. Mater. Sci. 30123

Dhumure S S and Lokhande C D 1993 Indian J. Pure \& Appl. Phys. 31512

Espevik S, Wu C and Bube R H 1971 J. Appl. Phys. 42 3513

Gadave K M, Jodgudri S A and Lokhande C D 1994 Thin Solid Films 2457

Johnson T H 1984 Proc. SPIE Int. Soc. Opt. Eng. 44360

Nair P K and Nair M T S 1989 Semicond. Sci. Technol. 4807

Nair P K, Nair M T S, Fernandez A and Ocampo M 1989 J. Phys. D: Appl. Phys. 22829

Nelson J B and Riley D P 1945 Proc. Phys. Soc. (London) 57 160

Popa A, Lisca M, Stancu V, Buda M, Pentia E and Botila T 2006 J. Optoelectron. Adv. Mater. 843

Reichelt K and Jiang X 1990 Thin Solid Films 19191

Sengupta S P and Chatterjee Partha 2002 PINSA A68 267

Ubale A U, Mankar R B, Daryapurkar A S, Raut R R and Sangawar V S 2007 Indian J. Phys. 81555

Ungar T and Borbely A 1996 Appl. Phys. Lett. 693173

Weber M J 2003 Handbook of optical material (California: University of California, CRC Press) p. 117 